\title{
Initial Findings on the Pursuit of Excellence in Teacher Training
}

\author{
Sor Heoh Saw \\ Office of Teaching and Learning, INTI International University, Nilai, Malaysia. \\ Email: sorheoh.saw@newinti.edu.my
}

Received December 30 ${ }^{\text {th }}, 2009$; revised March $2^{\text {nd }}, 2010$; accepted April $5^{\text {th }}, 2010$.

\begin{abstract}
This article reports the initial findings of a study carried out to evaluate the effectiveness of an academic skills training programme that prepares new university college teachers for teaching. Videotaped recordings of training, classroom observation of teaching and student evaluation of teaching were carried out and the results were analyzed to evaluate the effectiveness of the delivery and the activities for one of the module in achieving the stated objectives of the module. New teachers found the two activities in the Module 1 useful and were able to apply what they learned through these activities in their classroom teaching. The activities carried out supported the achievements of the intended outcomes of the module. However the new teachers demonstrated different levels of competence.
\end{abstract}

Keywords: Teachers Training, Higher Education

\section{Introduction}

Since Dearing's Report [1] universities in UK have acknowledged the importance of preparing new teaching staff with basic teaching skills as part of the quality assurance for teaching and learning. The commitment of the institutions is demonstrated by the setting up of units responsible for ensuring quality teaching and learning [2]. These units conduct training on teaching and learning, promote good practices and carry out research in teaching and learning. Studies carried out [3] have reported evidence of a range of positive changes in university teachers in the training group, and in their students, and a contrasting lack of change, or negative changes, in untrained teachers from the control group. Many institutions of higher learning in Malaysia have collaborative arrangements with UK universities to franchise their degree programmes. Likewise, these institutions are expected to provide training to their new teachers. They have also set up units to provide initial training to new teachers and more advanced trainings in specific areas relating to teaching and learning [4].

\section{Description of the Programme}

The Academic Skills Training programme consists of nine modules. The topics covered by these modules are classroom presentation skills, teaching methods and techniques, teaching and learning theories, assessment and evaluation, and microteaching. All newly appointed teachers are required to attend and complete the Academic Skills Training Programme before they commence teaching. Those with formal training and qualification in teaching can apply to be exempted from the programme.

The objectives for each of the nine modules in the programme are:

1) Classroom Presentation Skills-Module 1

Participants will learn how to start a lesson effectively using set induction. To guide the teachers and the students in a lecture, clear and precise instructional objectives are needed. Participants will also learn that to teach well in a class, they have to plan their instructional events that include the teaching media needed to bring the message across to the students.

2) Classroom Presentation Skills-Module 2

PowerPoint can be an effective instructional medium if the teachers know how to tap into its power. This module also touches on how to search for useful information in the Internet and use it to support classroom teaching. Participants are also introduced to the use of Learning Management System in supporting teaching and learning.

3) Teaching Method and Techniques-Module 3 and Module 4

Participants will learn the importance of active learning and ways to implement active learning in their classes. The process of active learning is then related to some of the common teaching methods currently used 
such as small group discussions, lectures, brainstorming and tutorials. The important technique of questioning effectively is discussed with emphasis placed on wait times and the use of different levels and types of questions in relation to Bloom's taxonomy.

4) Teaching and Learning Theories-Module 5

Participants will learn how the theories of behaviourism, cognitivism and constructivism help in the understanding of the process of learning, and their implications to teaching. The theory of multiple intelligences and its relationship to learning styles is examined with regard to implications to the teaching and learning situations. Participants will be able to relate the ideas gained from the learning theories as important guides in the structuring and implementation of effective teaching methods.

5) Assessment and Evaluation-Module 6 and Module 7

Participants will learn how to use the marking scheme to ensure fair assessment of learning outcomes. Assessment can also be used to support and improve teaching. They will also learn how to set the various types of test questions and new assessment methods such as performance assessment and portfolio assessment.

6) Outcome-based Education-Module 8
Participants will be introduced to outcome based education, distinguishing it from the current education. They will learn how to redesign the current contents, instructional strategies and assessment in line with outcome based education. The module also discusses its advantages and challenges.

7) Microteaching-Module 9

Participants are assigned into groups. Each group consists of between 8-10 participants. Each participant is allocated 15 minutes in a microteaching session which is videotaped. The group will view the videotape together with the trainer as facilitator. The aim is to learn from each other and not to criticise. The participants will comment on their own teaching in particular their strong points. The other participants are welcomed to give their suggestions.

\section{About this Study}

This study was carried out on Module 1 which is on classroom presentation skills. The duration of the module is 3 hours and it is delivered using a combination of lectures, video screenings and activities. Information on the module including the objectives, activities and teaching and learning strategies are presented in Table $\mathbf{1 .}$

Table 1. Module 1 - classroom presentation skills: module information, objectives, activities, teaching \& learning strategies

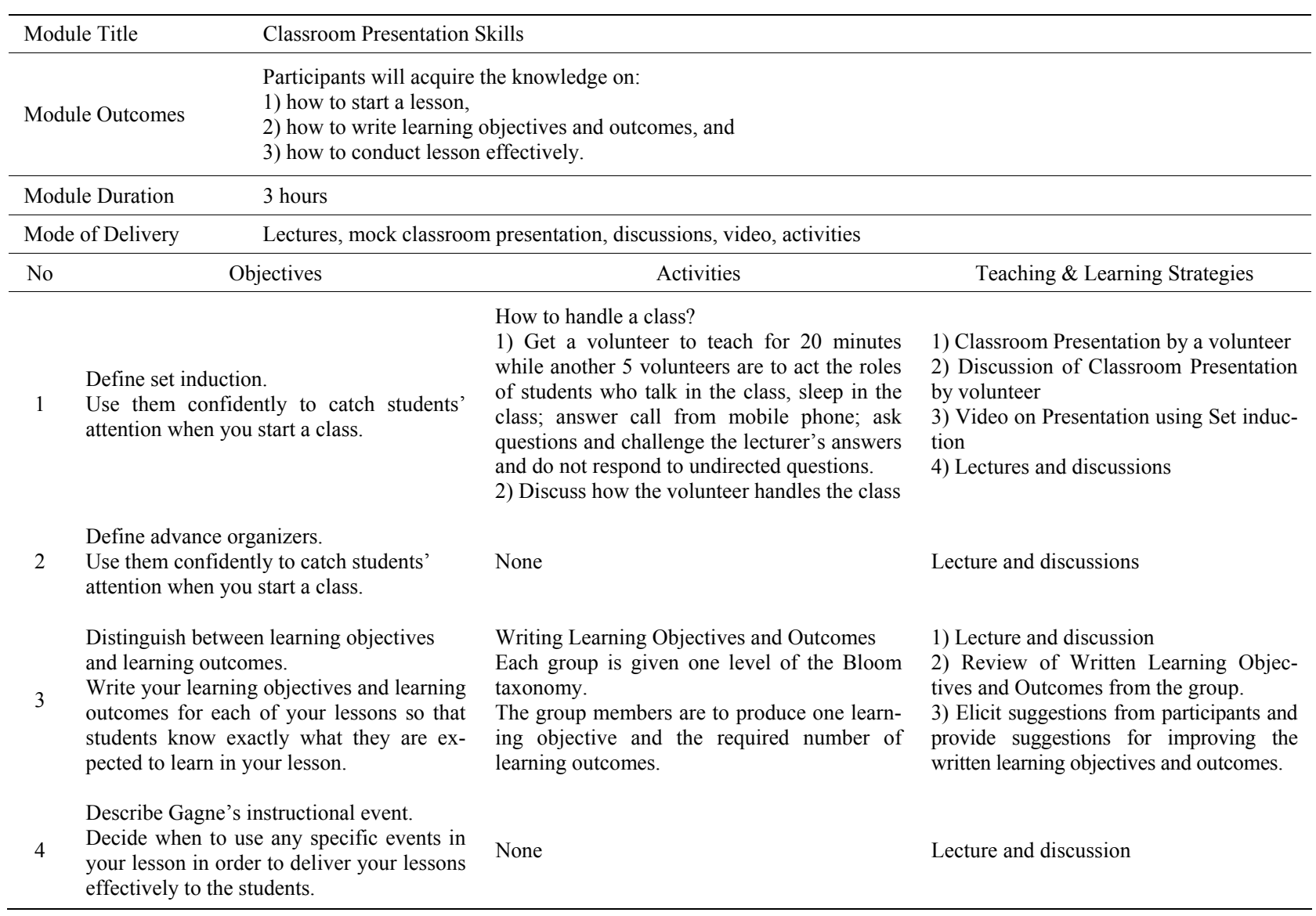




\section{Sample and Method}

This study was carried out for the training conducted in the Dec 2008 session attended by 23 teachers from various faculties, schools and centres. Out of these 23 teachers, 9 of them were newly appointed teachers who had completed all the nine modules and started teaching in the January 2009 session. This study focussed on these 9 newly appointed teachers who had no prior training in teaching. Four of the new teachers had less than 1 year teaching experience while the other five had more than 3 years of teaching experience.

Participants were given a quiz at the end of the module. They also completed a training feedback form at the end of the module. Post-training evaluations on the classroom presentation skills of the teachers were conducted through classroom observations of teaching carried out during the first semester of teaching by the new teachers. This was to determine whether the new teachers were applying the classroom presentation skills they learned in the training and to evaluate their competence. Student evaluation of classroom teaching provided a quantitative measure on the effectiveness of the teaching in general and the classroom presentation skills in particular.

This study also looked at the training materials given to the participants and the video recording of the training conducted, focussing on the activities carried out to determine the effectiveness of these activities in achieving the outcomes of the modules.

\section{Some Results of the Study}

From the quiz which consisted of 10 objective questions given immediately after the module, it was found that the average score of the participants was 6-7 questions correctly answered.

The post training survey questionnaires asked the participants whether the training provided had been beneficial to prepare them for their teaching. The analysis of the post training feedback showed that all the participants found the training beneficial and helped them to prepare for their teaching. In particular, they found that the training helped them to handle student's behaviour, prepare materials for lessons, apply active learning and get student involvement, capitalise on student's answers, identify and stop bad habits and promote best teaching practices.

The classroom observation of teaching was conducted for each of the nine new teachers. Generally it was observed that the new teachers practised what they learned and were able to apply set induction and learning objectives and outcomes in the classes. Most of them were observed to have demonstrated the use of set induction and learning objectives except for one new teacher with no prior teaching experience. Those with teaching experience accomplished them very well.
The results from the interviews supported the findings from the classroom observation of teaching that the activities for Module 1 were useful. They were able to apply the knowledge acquired through these activities in their teaching.

The first interviewee was a new teacher with no prior teaching experience. He said that he found the training and particularly the activities in Module 1 very helpful. $\mathrm{He}$ added that through Activity 1, he learned how to build rapport with students before starting the classes. He was able to apply it in his classes. He also learned how to capitalise on students incomplete responses and turned them into constructive responses and correct answers. He also found Activity 2 useful as it facilitated him in his preparation of lessons. He added that he observed that students often failed to see the importance of the learning outcomes statements. He observed that it was necessary for him to highlight at a specific point of the lessons where the outcome was achieved.

The second interviewee was a new lecturer with more than 3 years of teaching experience but no formal training in teaching. He found both Activity 1 and Activity 2 useful. He highlighted the ice-breaking with students before starting the lessons as the most useful skill he learned from Activity 1 and he practised it in his classes. The learning outcomes were useful as they informed the students what they can expect to learn from the lessons. He added that he found Bloom's taxonomy very useful and he was able to apply the knowledge for setting final examination questions.

A quantitative analysis was also carried out from the data obtained through the questionnaires on Student Evaluation of Teaching. Seven of them scored above $80 \%$ meeting the benchmark of the institution; whilst two of the new teachers with no prior teaching experience scored about $60 \%$.

\section{Conclusions}

Initial findings showed that the participants found the two activities in Module 1 useful and were able to apply them in their classroom teaching. The activities carried out supported the achievements of the stated objectives of the modules. However the new teachers demonstrated different levels of competence. More activities and case studies relating to classroom presentation skills may help to improve the effectiveness of the module.

\section{Acknowledgements}

The writers wish to acknowledge the Academic Development Centre, University of Malaya for their continuous support for this study and for sharing the same passionate commitment to promote best practices in teaching through action research. 


\section{REFERENCES}

[1] R. Dearing, "Higher Education in the Learning SocietySummary Report," The National Committee of Inquiry into Higher Education, Her Majesty's Stationery Office, London, 1997.

[2] G. Badley, "Improving Teaching in British Higher Education," Quality Assurance in Education, Vol. 7, No. 1, 1999, pp. 35-40.

[3] G. Gibbs and M. Coffey, "The Impact of Training of University Teachers on their Teaching Skills, their Ap- proach to Teaching and the Approach to Learning of their Students," Active Learning in Higher Education, Vol. 5, No. 1, 2004, pp. 87-100.

[4] C. Farrugis, "A Continuing Professional Development Model for Quality Assurance in Higher Education," Quality Assurance in Education, Vol. 4, No. 2, 1996, pp. 28-34.

[5] M. H. Cheng and K. C. Pang, "Teacher Socialization: Implications for the Design and Management of Initial Teacher Education Programmes," Education and Training, Vol. 39, No. 5, 1999, pp. 195-204. 